\title{
Validation of Algorithms for Donning and Doffing Personal Protective Equipment during the COVID-19 Pandemic
}

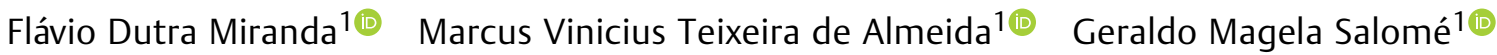 \\ 1 Professional Master's Program in Applied Health Sciences, \\ Universidade do Vale do Sapucaí, Pouso Alegre, MG, Brazil \\ J Coloproctol 2021;41(4):367-374 \\ Address for correspondence Geraldo Magela Salomé, RN, PhD, \\ Universidade do Vale do Sapucaí, Av. Prefeito Tuany Toledo 470, CEP: \\ 37550-000 Pouso Alegre, MG, Brasil \\ (e-mail: salomereiki@univas.edu.br)
}

\begin{abstract}
Keywords

- coronavirus infection

- protective devices

- pressure injury

- use of equipment and supplies

- algorithms

Introduction The prolonged or incorrect use of facial masks, respirators and glasses or visors results in friction, pressure and shear forces that constantly act on the facial skin, leading to lesions and dermatitis.

Objective To develop and validate algorithms to guide health professionals in the correct use of personal protective equipment (PPE) and indicate preventive measures against skin injuries caused by inappropriate use during the COVID-19 pandemic.

Methods For the develoment of the algorithms, an integrative literature review was performed using the following databases: PubMed, SciELO, and LILACS. The algorithms were evaluated by 59 health professionals (nurses, doctors, and physiotherapists), using the Delphi technique. A content validity index (CVI) was used for the statistical analysis.

Results The experts classified the items of the algorithms from fully inadequate to fully adequate in the first round of consultations, and from partially adequate to fully adequate in the second round. The overall CVI values were of 0.83 and 1.0 in the first and second rounds respectively.

Conclusion The algorithms validated by the expert panel can be used by health professionals when donning and doffing PPE, and to prevent the facial-skin lesions caused by their use.
\end{abstract}

\section{Introduction}

At the end of 2019, a Chinese doctor announced to the world a new disease caused by a coronavirus strain: severe acute respiratory syndrome coronavirus 2 (SARS-CoV-2). This infection was named by the World Health Organization (WHO) coronavirus disease 2019 (COVID-19). ${ }^{1}$ The WHO declared the outbreak a Public Health Emergency of International Concern on January 30, 2020, and a pandemic on March 11,
$2020 .^{1-3}$ The disease is highly transmissible by infected respiratory droplets and contact, especially in closed locations with poor ventilation and low light, and in hospital environments. An infected person transmits the virus to two or three other people, depending on environmental conditions. Regarding COVID-19, this transmission rate, called the reproductive number, ranges from 2.0 to $3.5 .4,5$

Several health professionals at the front line of the COVID-19 pandemic response are being infected through received

November 30, 2020 accepted after revision June 15, 2021
DOI https://doi.org/

10.1055/s-0041-1739167. ISSN 2237-9363.

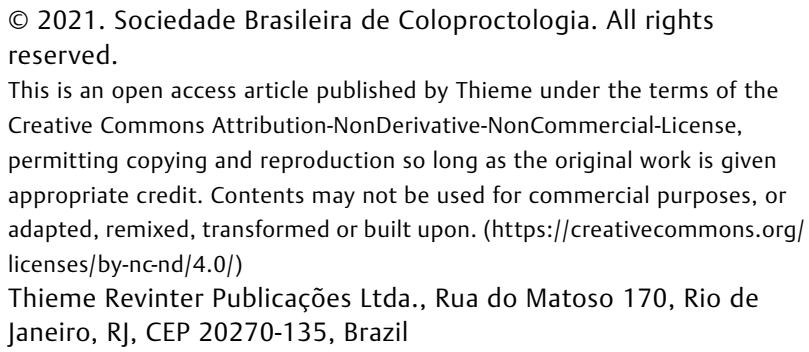


facial injuries caused by the use of personal protective equipment (PPE). It is very important that health institutions provide PPE to these professionals, as well as training regarding their use, because they are indispensable to comply with the standard measures of prevention of infections by droplets and contact during the pandemic., 6

Personal protective equipment is every device designed to protect the physical integrity of the worker, and include gloves, glasses or facial protectors, respiratory protective equipment (RPE), aprons, and those for lower-limb. It cannot be ignored that hand hygiene is one of the most important standard precautions to prevent contamination and the spread of the virus. Prolonged or incorrect use of face masks, RPE and glasses or visors results in constant friction, pressure, and shear forces on facial skin, leading professionals to suffer lesions and dermatitis. ${ }^{8,9}$

In this sense, it is important to develop educational technology, manuals, booklets, algorithms, and applications that provide appropriate information about the techniques for the use of PPE and on preventive actions and therapeutic approaches for facial-skin lesions caused by them. Thus, professionals will be providing damage-free care, safely, and without risk to the patient, avoiding being contaminated and preventing facial-skin lesions.

Algorithms constitute a finite sequence of well-defined intructions that can be carried out systematically. They are simple, direct, and easily-accessible instruments, commonly employed in the health field to provide a complete view of the clinical process and assist in decision making. ${ }^{10-12}$

The present study aimed to develop and validate three algorithms to provide guidance to health professionals on the correct use of PPE and to recommend preventive measures related to facial-skin lesions caused by the use of PPE during the COVID-19 pandemic.

\section{Methods}

A methodological study on the development of a technological tool.

For the development of the algorithms, a content survey was initially carried out through an integrative literature review. ${ }^{13}$ The following stages for the conduction of the research were defined: identification of the subject and selection of the research question, establishment of criteria for the inclusion and exclusion of studies, definition of the information to be extracted from the selected studies, categorization and evaluation of the studies included, interpretation of the results, presentation of the review, and synthesis of the knowledge obtained. ${ }^{14}$

The subject was "facial-skin lesions caused by the use of PPE during the COVID-19 pandemic".

The objective of the present study was to answer the following guiding questions: what kinds of PPE are used by health professionals at the front line of the COVID-19 pandemic response, and what techniques are used for donning and doffing? What are the preventive measures available in the literature to avoid facial-skin lesions caused by the use of PPE during the COVID-19 pandemic?
For the composition of the appropriate question for the resolution of the clinical question studied, the PICO strategy ${ }^{15}$ was used, in which $\mathrm{P}$ corresponds to the population (health professionals), I, to intervention (technique for donning and doffing PPE, preventive measures for facial-skin lesions), $\mathrm{C}$, to comparison (does not apply), and $\mathrm{O}$, to the outcome (protocol in the form of an algorithm).

\section{Literature review}

We performed an integrative review of the literature found in the health sciences databases Medical Literature Analysis and Retrieval System Online (MEDLINE), Scientific Electronic Library Online (SciELO) and Latin American and Caribbean Literature in Health Sciences (Literatura Latinoamericana y del Caribe en Ciencias de la Salud, LILACS, in Spanish).

The following controlled descriptors in health sciences were used: COVID-19; pressure injury related to medical device, and equipment and provisions. The search strategy used different combinations of the descriptors, as well as the Boolean operator AND in Portuguese, Spanish and English.

For the selection of publications, the following inclusion criteria were adopted: original studies published between 2015 and 2020, directly related to the subject, with the full text available. The exclusion criteria were: dissertations, monographs, technical reports, and articles not related to the subject under study, as well as duplicate studies.

First, the titles and abstracts were read independently by two researchers to ensure that the texts contemplated the guiding question of the review and met the inclusion criteria. In case of doubt regarding a publication, it was initially included, and the decision on its selection was only made after the full text was read.

To classify the level of evidence of the selected studies, the categories of the Agency for Healthcare Research and Quality were adopted, covering six levels: level 1: evidence resulting from meta-analysis of multiple randomized controlled clinical trials; level 2: evidence obtained from individual studies with experimental design; level 3: evidence from quasiexperiments; level 4: evidence from descriptive (non-experimental) studies or those with a qualitative approach; level 5: evidence from case or experience reports; and level 6: evidence based on expert opinions.

\section{Structuring and validation of algorithms}

The structuring of the algorithms comprised the description of the technique for donning and doffing PPE used by health professionals during the COVID-19 pandemic. Measures for the prevention of injuries caused by the use of PPE, including the types and the technique for the use of facial devices, and the technique for the use of creams and skinbarrier protectors, which should be adopted before, during and after the use of PPE, have also been described.

To validate the algorithms, we used the Delphi technique, an interactive forecasting method which relies on a panel of experts. The content of the study instruments is evaluated by the panel through questionnaires in search of a consensus between 50 and $100 \%$ among the evaluators. ${ }^{15-18}$ 
The experts were selected by means of snowball sampling, in which, when a health professional who fits the established inclusion criteria is identified, they are asked to indicate other participants. The Brazilian Association of Technical Standards (Associação Brasileira de Normas Técnicas, ABNT, in Portuguese) recommends a minimum sampling of ten participants.

Physicians, physiotherapists, and nurses who were at the front line of the COVID-19 pandemic response were included in the study. The professionals who agreed to participate in the research but did not answer the questionnaire within eight days were excluded.

An invitation letter was sent to 110 selected professionals, including an initial personal presentation and explanations regarding the research topic, copy of the approval of the institutional Ethics in Research Committee, a description of the task assigned to the experts, and the communication of the eight-day deadline to fill out and return the questionnaire for each round of the evaluation. The invitation letter also included, as attachment, the questionnaire to evaluate the content of the algorithms, including the following items: graphic presentation, ease of reading, vocabulary, sequence of algorithms, types of PPE used in the COVID-19 pandemic, techniques for donning and doffing PPE, preventive measures and therapeutic approaches (types and techniques for the use of facial devices, technique for the use of creams and skin-barrier protectors), and skin care before, during, and after the use of PPE.

A Likert scale was used in the questions regarding the evaluation of the algorithm, with the following options: "partially inadequate", "fully inadequate", "partially adequate", and "fully adequate"; there was also a section for the experts to make suggestions.

In the data analysis, the answers classified as "partially adequate" or "fully adequate" were considered validated. The suggestions presented by the experts were evaluated and, based on them, adjustments were made so that the content of the algorithms was considered validated. Questions whose answers were "partially inadequate" or "fully inadequate" were sent back to the experts in the second round of evaluation with suggestions made for retrial, seeking to reach a consensus among the judges.

The validity of the content of the algorithms was verified based on a content validity index (CVI), which was calculated based on the proportion of the number of "partially adequate" and "fully adequate" answers. To verify content validity, agreement values $>0.8$ was adopted. ${ }^{19}$

The present study was approved by the Ethics in Research Committee of Universidade do Vale do Sapucaí under opinion number $4,273,510$.

\section{Findings}

A total of 12,535 articles were identified through the database search, and 4,523 were excluded because they were duplicates. Thus, 8,012 articles were selected for the reading of the title, and 163, for the reading of the abstract, which resulted in a sample of 112 articles for the reading of the full text. From these, 86 were excluded because they did not answer the guiding question, which led to a total of 26 articles selected for the development of the algorithms.

Three algorithms were developed comprising the techniques for donning (-Figure 1) and doffing (-Figure 2), and the preventive measures (-Figure $\mathbf{3}$ ).

In the validation study of the algorithms, we included 59 physicians, nurses, and physiotherapists working at the front line of the COVID-19 pandemic response, who agreed to participate in the study and sent the completed questionnaire within the requested time frame.

The results obtained in the first and second evaluations of the expert panelregarding the content of the algorithms can be found in - Table 1 and - Table 2 respectively.

In the first evaluation, the panel classified the algorithms from "fully inadequate" to "fully adequate" (-Table 1 ), but none of the algorithms items reached an agreement $>80 \%$ among the experts, as required for the validation. The CVI ranged from 0.76 to 0.86 , which corresponds to a good content.

After corrections based on the experts' comments, all items of the algorithms were reevaluated as "partially adequate" or "fully adequate" (- Table $\mathbf{2}$ ). In the second evaluation, the experts reached a consensus, with a CVI of 1.0, which characterizes the content of the algorithms as excellent.

\section{Discussion}

Algorithms are used to direct clinical and care decisions, preventive measures and disease treatment, hospital management, and public health. They should be validated and developed based on scientific evidence. ${ }^{10,12,19,20}$

The adoption of the prevention measures against infection recommended by the WHO should be reinforced among the general population. For health professionals, the use of PPE and hand washing must be mandatory to aid suspected or confirmed cases of COVID-19. ${ }^{21}$

The role of PPE in protecting the health of health workers in the current pandemic is fundamental. With the risk of biological contamination, they act as barriers that can prevent infection, but their improper or prolonged use can cause facial injuries. It is important that institutions develop descriptive protocols or algorithms, and that professionals are trained. ${ }^{22}$ A study ${ }^{23}$ on training and education in the context of highly-infectious diseases showed that health professionals felt the need for quality protocols and training on the use of PPE. Thus, it is necessary that, during the COVID-19 pandemic, institutions implement protocols and provide training that enables the practical implementation of the appropriate technique among all participants to minimize technical errors, which leads to reduction in the contamination risk and the prevention of injuries caused by inappropriate use.

In the first evaluation of the algorithms, several suggestions were made regarding the donning and doffing of PPE and measures to prevent facial lesions. The adjustments suggested were made, and the algorithms were sent back 


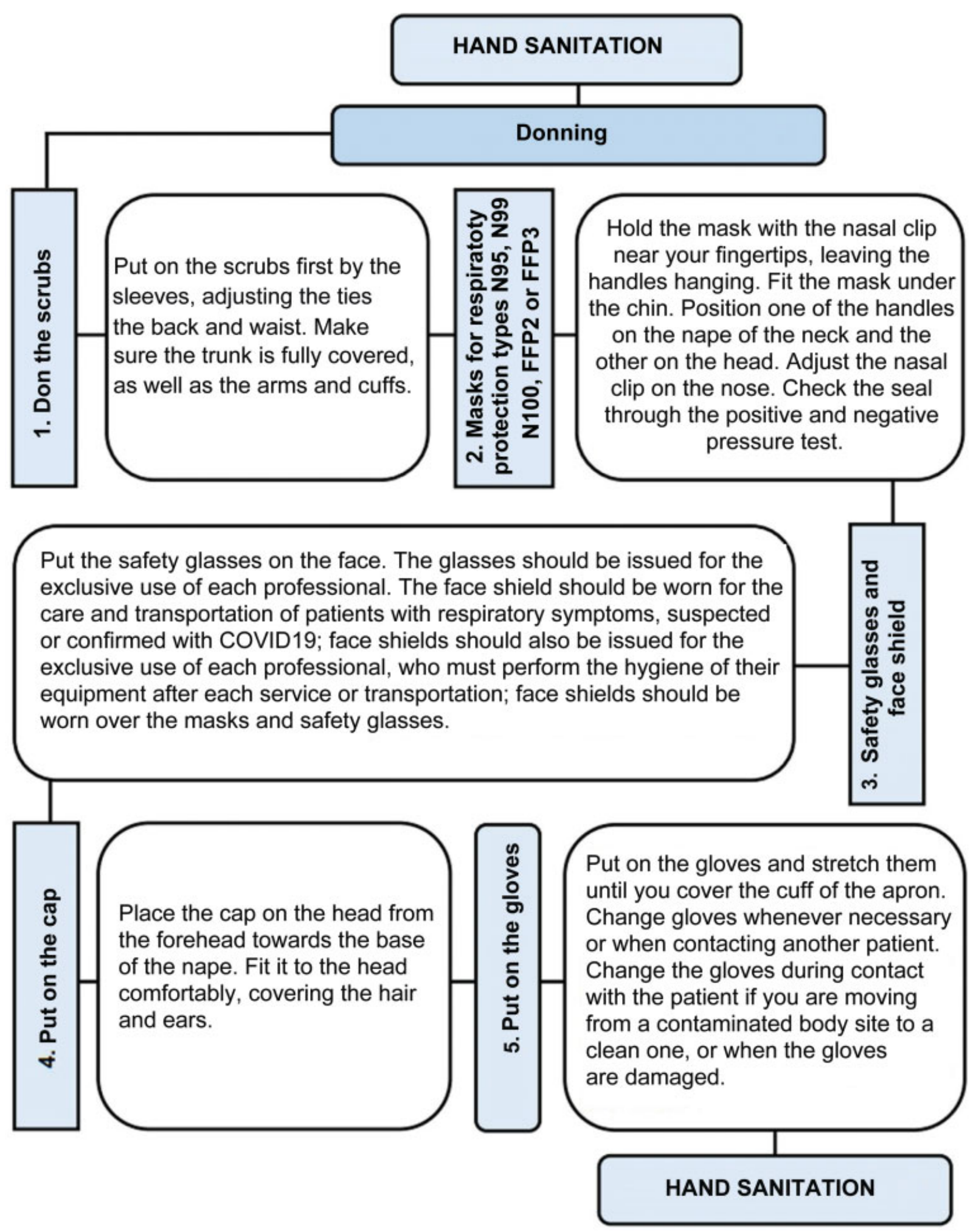

Fig. 1 Algorithm to guide health professionals in the donning of PPE during the COVID-19 pandemic.

for the second evaluation, in which the experts approved them by consensus.

Algorithms for the clinical practice of health professionals should be developed based on scientific evidence, with the purpose of assisting in technical, clinical, administrative, and financial procedures. This tool aims to improve the care provided to the patient, and optimize the cost-benefit ratio of treatment and the adoption of preventive measures by the professionals who provide care, seeking to reduce as much as possible the risks of infection or injuries. ${ }^{24,25}$

During the validation process, the algorithms underwent some changes, which contributed to a better understanding, 


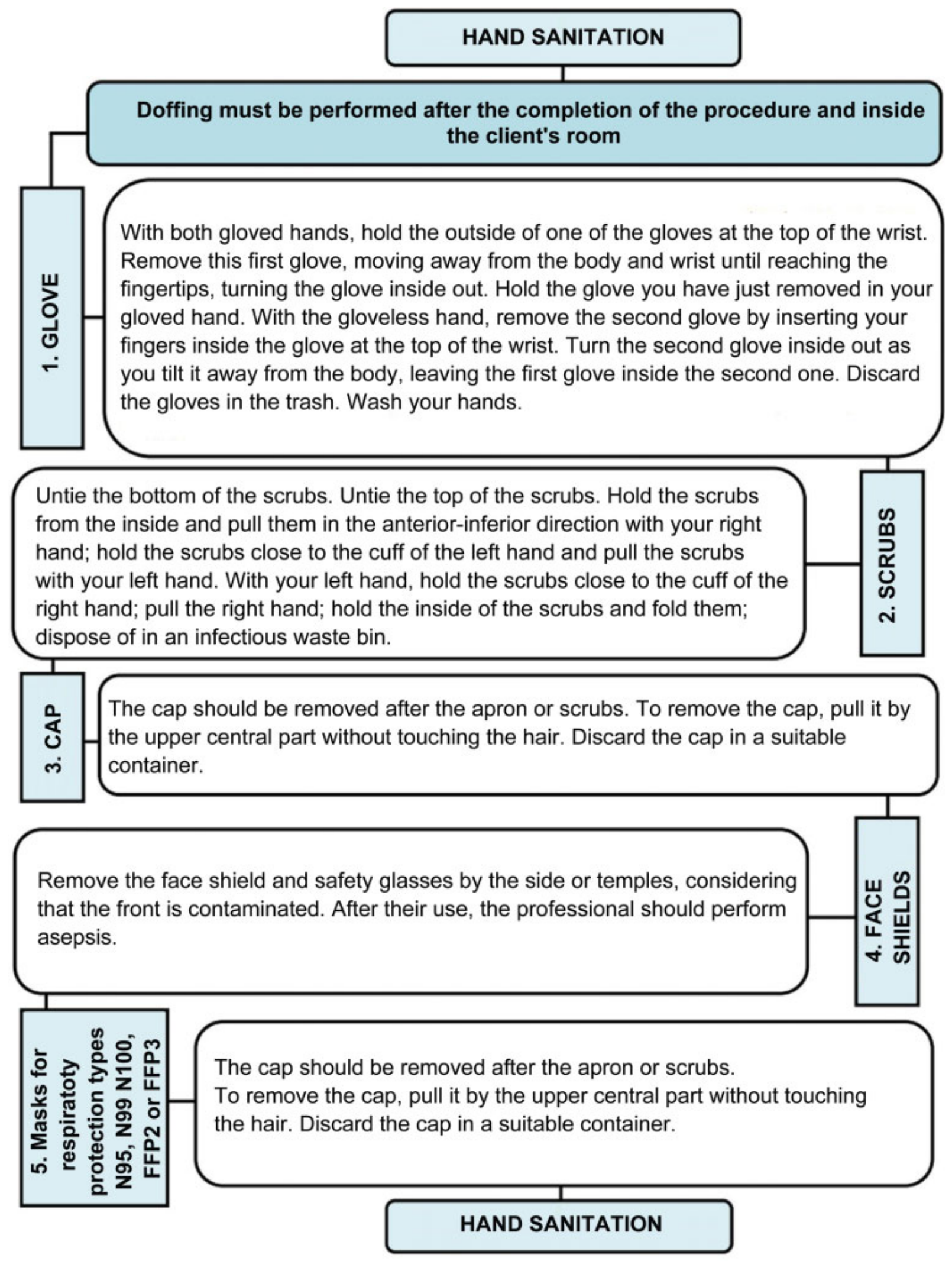

Fig. 2 Algorithm for doffing PPE during the COVID-19 pandemic.

effectiveness and implementation of algorithms at our, enabling the professional to use the correct technique for donning and doffing and, consequently, prevent facial injuries, resulting in care with minimal risk. ${ }^{11,12,23}$
In the present study, algorithms were developed after an integrative review of the literature to assist the professional in the clinical practice. Algorithms guide the healthcare team in the decision-making process, provide a broad view of an 


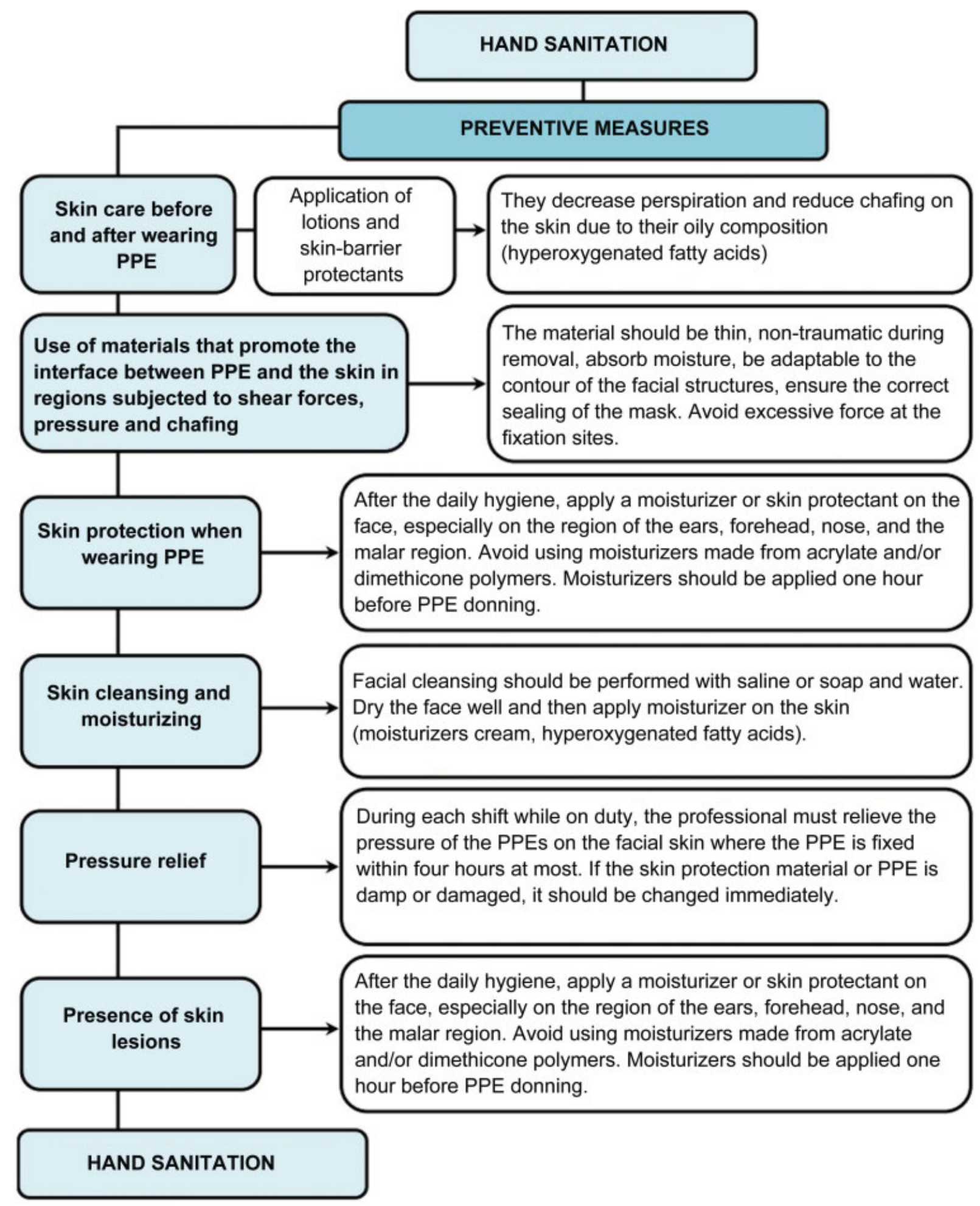

Fig. 3 Algorithm to prevent injury caused by the use of PPE during the COVID-19 pandemic.

entire process, and promote better care management. ${ }^{25-28}$ After their development, algorithms should be evaluated for their effectiveness and usefulness. ${ }^{19,25-28}$

\section{Final Considerations}

The algorithms developed after an integrative review of the literature and validated by the panel of experts can be applied in the donning and doffing of PPE, and in the prevention of facial-skin lesions caused by their use. These algorithms provide theoretical and practical foundations to health professionals and contribute to the standardization of the donning and doffing techniques, enabling professionals to prevent facial-skin injuries and infection by COVID-19, resulting in an improvement in individualized and personalized care. 
Table 1 Classification of the content of the algorithms by the expert panel during the first evaluation cycle

\begin{tabular}{|c|c|c|c|c|c|c|c|c|c|c|c|}
\hline \multirow[t]{3}{*}{ First evaluation: summarized questions } & \multicolumn{8}{|c|}{ Item suitability } & & & \\
\hline & \multicolumn{2}{|c|}{ (1) } & \multicolumn{2}{|l|}{ (2) } & \multicolumn{2}{|l|}{ (3) } & \multicolumn{2}{|l|}{ (4) } & \multicolumn{2}{|c|}{ Total } & \multirow[t]{2}{*}{ CVI } \\
\hline & $\mathbf{n}$ & $\%$ & $\mathbf{n}$ & $\%$ & $\mathrm{n}$ & $\%$ & $\mathbf{n}$ & $\%$ & $\mathbf{n}$ & $\%$ & \\
\hline Is the content suitable for the target audience? & 0 & 0 & 9 & 15.3 & 16 & 27.1 & 34 & 57.6 & 59 & 100 & 0.84 \\
\hline Is the text sequence logical and coherent? & 0 & 0 & 8 & 13.6 & 12 & 20.3 & 39 & 66.1 & 59 & 100 & 0.81 \\
\hline Does the content make learning easier? & 0 & 0 & 9 & 15.3 & 29 & 49.2 & 21 & 35.6 & 59 & 100 & 0.86 \\
\hline Is the vocabulary accessible? & 1 & 1.7 & 10 & 16.9 & 10 & 16.9 & 38 & 64.4 & 59 & 100 & 0.84 \\
\hline Is the language easily comprehensible? & 0 & 0 & 9 & 15.3 & 7 & 11.9 & 43 & 72.9 & 59 & 100 & 0.82 \\
\hline $\begin{array}{l}\text { Does the content clarify doubts about the } \\
\text { subject? }\end{array}$ & 0 & 0 & 14 & 16.9 & 14 & 30.5 & 31 & 52.5 & 59 & 100 & 0.76 \\
\hline Graphic presentation & 0 & 0 & 9 & 15.3 & 10 & 16.9 & 40 & 67.8 & 59 & 100 & 0.81 \\
\hline $\begin{array}{l}\text { WHO-recommended PPE for use in the } \\
\text { COVID-19 pandemic }\end{array}$ & 0 & 0 & 9 & 15.3 & 25 & 42.4 & 25 & 42.4 & 59 & 100 & 0.83 \\
\hline Interface materials between PPE and the skin & 0 & 0 & 9 & 15.3 & 7 & 11.9 & 43 & 72.9 & 59 & 100 & 0.79 \\
\hline Techniques for donning and doffing PPE & 0 & 0 & 11 & 19.3 & 7 & 12.3 & 39 & 68.4 & 57 & 100 & 0.84 \\
\hline $\begin{array}{l}\text { Guidelines for relief of pressure due to } \\
\text { the use of PPE }\end{array}$ & 0 & 0 & 11 & 19.0 & 5 & 8.6 & 42 & 72.4 & 58 & 100 & 0.79 \\
\hline Care before and after the wearing PPE & 0 & 0 & 10 & 16.9 & 10 & 16.9 & 39 & 66.1 & 59 & 100 & 0.83 \\
\hline Skin cleansing and moisturizing technique & 0 & 0 & 9 & 15.3 & 6 & 10.2 & 44 & 74.6 & 59 & 100 & 0.84 \\
\hline General CVI & & & & & & & & & & & 0.831 \\
\hline
\end{tabular}

Abbreviations: CVI, content validity index; PPE, personal protective equipment; WHO, World Health Organization; COVID-19, coronavirus disease 2019.

Notes: (1) fully inadequate; (2) partially inadequate; (3) partially adequate; (4) fully adequate.

Table 2 Classification of the content of the algorithms by the expert panel during the second evaluation cycle

\begin{tabular}{|c|c|c|c|c|c|c|c|c|c|c|c|}
\hline \multirow[t]{3}{*}{ Second evaluation: summarized questions } & \multicolumn{8}{|c|}{ Item suitability } & & & \\
\hline & \multicolumn{2}{|c|}{ (1) } & \multicolumn{2}{|c|}{$(2)$} & \multicolumn{2}{|l|}{ (3) } & \multicolumn{2}{|l|}{ (4) } & \multicolumn{2}{|c|}{ Total } & \multirow[t]{2}{*}{ CVI } \\
\hline & $\mathrm{n}$ & $\%$ & $\mathbf{n}$ & $\%$ & $\mathbf{n}$ & $\%$ & $\mathbf{n}$ & $\%$ & $\mathbf{n}$ & $\%$ & \\
\hline Is the content suitable for the target audience? & 0 & 0 & 0 & 0 & 7 & 11.9 & 52 & 88.1 & 59 & 100 & 1.0 \\
\hline Is the text sequence logical and coherent? & 0 & 0 & 0 & 0 & 12 & 20.3 & 47 & 79.7 & 59 & 100 & 1.0 \\
\hline Does the content make learning easier? & 0 & 0 & 0 & 0 & 12 & 20.3 & 47 & 79.7 & 59 & 100 & 1.0 \\
\hline Is the vocabulary accessible? & 0 & 0 & 0 & 0 & 25 & 42.4 & 34 & 57.6 & 59 & 100 & 1.0 \\
\hline Is the language easily comprehensible? & 0 & 0 & 0 & 0 & 28 & 47.5 & 31 & 52.5 & 59 & 100 & 1.0 \\
\hline Does the content clarify doubts about the subject? & 0 & 0 & 0 & 0 & 6 & 10.2 & 53 & 89.8 & 59 & 100 & 1.0 \\
\hline Graphic presentation & 0 & 0 & 0 & 0 & 13 & 22.0 & 46 & 78.0 & 59 & 100 & 1.0 \\
\hline WHO-recommended PPE for use in the COVID-19 pandemic & 0 & 0 & 0 & 0 & 10 & 16.9 & 49 & 83.1 & 59 & 100 & 1.0 \\
\hline Interface materials between PPE and the skin & 0 & 0 & 0 & 0 & 12 & 20.3 & 47 & 79.7 & 59 & 100 & 1.0 \\
\hline Techniques for donning and doffing PPE & 0 & 0 & 0 & 0 & 9 & 15.3 & 50 & 84.7 & 59 & 100 & 1.0 \\
\hline Guidelines for pressure relief due to the use of PPE & 0 & 0 & 0 & 0 & 22 & 37.3 & 37 & 62.7 & 59 & 100 & 1.0 \\
\hline Care before and after the wearing PPE & 0 & 0 & 0 & 0 & 12 & 20.3 & 47 & 79.7 & 59 & 100 & 1.0 \\
\hline Skin cleansing and moisturizing technique & 0 & 0 & 0 & 0 & 11 & 18.6 & 48 & 81.4 & 59 & 100 & 1.0 \\
\hline General CVI & & & & & & & & & & & 1.0 \\
\hline
\end{tabular}

Abbreviations: CVI, content validity index; PPE, personal protective equipment; WHO, World Health Organization; COVID-19, coronavirus disease 2019.

Notes: (1) fully inadequate; (2) partially inadequate; (3) partially adequate; (4) fully adequate. 
Funding

The authors declare that the present study did not receive any external funding.

\section{Conflict of interests}

The authors have no conflict of interests to declare.

\section{References}

1 World Health Organization. Coronavirus disease 2019 (COVID-19). Situation report -87. 2020. [citado em 2020 maio 02]. Disponível em: https://www.who.int/docs/default-source/coronaviruse/ situation-reports/20200416-sitrep-87-covid-19.pdf?sfvrsn= 9523115a_2

2 Freitas BHBM, Alves MDSM, Gaíva MAM. Prevention and control measures for neonatal COVID-19 infection: a scoping review. Rev Bras Enferm 2020;73(Suppl 2):e20200467. Doi: 10.1590/00347167-2020-0467

3 Baig AM, Khaleeq A, Ali U, Syeda H. Evidence of the COVID-19 virus targeting the CNS: tissue distribution, host-virus interaction, and proposed neurotropic mechanisms. ACS Chem Neurosci 2020;11(07):995-998. Doi: 10.1021/acschemneuro.0c00122

4 Deng CX. The global battle against SARS-CoV-2 and COVID-19. Int J Biol Sci 2020;16(10):1676-1677. Doi: 10.7150/ijbs.45587

5 Medeiros EA. A luta dos profissionais de saúde no enfrentamento da COVID-19. Acta Paul Enferm 2020;33:e-EDT20200003. Doi: 10.37689/acta-ape/2020EDT0003

6 Oliveira HC, Souza LC, Leite TC, Campos JF. Personal Protective Equipment in the coronavirus pandemic: training with Rapid Cycle Deliberate Practice. Rev Bras Enferm 2020;73(Suppl 2): e20200303. Doi: 10.1590/0034-7167-2020-0303

7 Holland M, Zaloga DJ, Friderici CS. COVID-19 Personal Protective Equipment (PPE) for the emergency physician. Vis J Emerg Med 2020;19:100740. Doi: 10.1016/j.visj.2020.100740

8 Gefen A, Alves P, Ciprandi G, et al. Device-related pressure ulcers: SECURE prevention. J Wound Care 2020;29(Supl. 2a)S1-S52 Doi: 10.12968/jowc.2020.29.Sup2a.S1

9 Alves P, Moura A, Vaz A, et al. PREPI/COVID19. Prevenção de lesões cutâneas causadas pelos Equipamentos de Proteção Individual (máscaras faciais, respiradores, viseiras e óculos de proteção). APTFeridas 2020. Disponível em: https://www.aptferidas.com/ Ficheiros/COVID19/APTFeridas\%20-\%20RECOMENDAC\%CC\%A7A \%CC\%830\%20PREPI-COVID19.pdf

10 Carvalho MRF, Salomé GM, Ferreira LM. Construction and validation of algorithm for treatment of pressure injury. J Nurs UFPE Online 2017;11(Supl. 10):4171-4183https://periodicos.ufpe. br/revistas/revistaenfermagem/article/viewFile/231180/25157

11 Salomé GM, Rocha CA, Miranda FD, Alves JR, Dutra RAA, Tenório AG. Algorithms for prevention and treatment of incontinenceassociated dermatitis. ESTIMA Braz J Enterostomal Ther 2020;18: e1320. Doi: 10.30886/estima.v18.837_IN

12 Cunha DRD, Salomé GM, Massahud MR Junior, Mendes B, Ferreira LM. Development and validation of an algorithm for laser appli- cation in wound treatment. Rev Lat Am Enfermagem 2017;25: e2955. Doi: 10.1590/1518-8345.1998.2955

13 Mendes KDS, Silveira RCCP, Galvão CM. Revisão integrativa: método de pesquisa para a incorporação de evidências na saúde e na enfermagem. Texto Contexto Enferm 2008;17(04):758-764https://www.redalyc.org/pdf/714/71411240017.pdf

14 Whittemore R, Knafl K. The integrative review: updated methodology. J Adv Nurs 2005;52(05):546-553. Doi: 10.1111/j.13652648.2005.03621.x

15 da Costa Santos CM, de Mattos Pimenta CA, Nobre MRC. The PICO strategy for the research question construction and evidence search. Rev Lat Am Enfermagem 2007;15(03):508-511. Doi: 10.1590/s0104-11692007000300023

16 Grant JS, Davis LL. Selection and use of content experts for instrument development. Res Nurs Health 1997;20(03):269-274. Doi: 10.1002/(sici)1098-240x(199706)20:3<269:aid-nur9>3.0.co;2-g

17 Pasquali L. Instrumentação psicológica: fundamentos e práticas. Porto Alegre, RS: Artmed; 2010

18 Wright JTC, Giovinazzo RA. Delphi uma ferramenta de apoio ao planejamento prospectivo. Cad Pesqui Adm. 2000;1(12):54-65

19 Santos AC, Dutra RAA, Salomé GM, Ferreira LM. Construction and internal reliability of an algorithm for choice cleaning and topical therapy on wounds. J Nurs UFPE Online 2018;12(05):680-685. Doi: 10.5205/1981-8963-v12i5a230675p1250-1262-2018

20 Alves DFS, Almeida AO, Silva JLG, Morais FI, Dantas SRPE, Alexandre NMC. Translation and adaptation of the Bates-Jensen wound assessment tool for the Brazilian culture. Texto Contexto Enferm 2015;24(03):826-833. Doi: 10.1590/0104-07072015001990014

21 Belasco AGS, Fonseca CDD. Coronavirus 2020. Rev Bras Enferm 2020;73(02):n2. Doi: 10.1590/0034-7167-2020730201

22 Almeida IM. Proteção da saúde dos trabalhadores da saúde em tempos de COVID-19 e respostas à pandemia. Rev Bras Saúde Ocup 2020;45:e17. Doi: 10.1590/SciELOPreprints.140

23 Le AB, Buehler SA, Maniscalco PM, et al. Determining training and education needs pertaining to highly infectious disease preparedness and response: A gap analysis survey of US emergency medical services practitioners. Am J Infect Control 2018;46(03): 246-252. Doi: 10.1016/j.ajic.2017.09.024

24 Salomé GM, Ferreira LM. Developing a mobile app for prevention and treatment of pressure injuries. Adv Skin Wound Care 2018;31 (02):1-6. Doi: 10.1097/01.ASW.0000529693.60680.5e

25 Salomé GM, Dutra RAA. Prevention of facial injuries caused by personal protective equipment during the COVID-19 pandemic. Rev Bras Enferm 2021;74(Suppl 1):e20201219. Doi: 10.1590/0034-7167-2020-121

26 Cunha JB, Dutra RAA, Salomé GM. Elaboração de algoritmo para avaliação e tratamento de ferida. ESTIMA Braz J Enterostomal Ther. 2018;16:e2018. Doi: 10.30886/estima.v16.524_PT

27 Salomé GM, Pontes BCD. Pressure Ulcers during the COVID-19 pandemic. J Nurs UFPE Online 2021;15:e246189. Doi: 10.5205/1981-8963.2021.246189

28 Salomé GM. Algoritmo para paramentação, desparamentação e prevenção de lesões faciais: covid-19. Rev Enferm Contemp 2021; 10(02):. Doi: 10.17267/2317-3378rec.v10i2.3317 